\title{
LA HUELGA PACÍFICA EN LA NEGOCIACIÓN COLECTIVA Y EL PROYECTO DE REFORMA LABORAL: UN ANALISIS CRÍTICO
}

\section{NON-VIOLENT STRIKE DURING THE COLLECTIVE BARGAINING PROCESS AND THE LABOR BILL: CRITIC ANALYSIS}

\author{
MARIA FERNANDA ESPINOSA MEZA* \\ MARIA JOSE CHIBLE VILLADANGOS**
}

\begin{abstract}
RESUMEN: En el presente trabajo las autoras indagan en torno a la noción de huelga y su carácter pacífico en el marco del proyecto de reforma laboral. El objetivo es evidenciar como, al materializarse la huelga, y una vez ponderada la libertad sindical con otros derechos fundamentales, la libertad sindical prima amparando una serie de episodios de conflicto y enfrentamiento entre organización sindical y empleador, razonamiento que en el marco del proyecto de reforma laboral pierde fundamento.
\end{abstract}

Palabras clave: Negociación Colectiva, Huelga Pacifica, Huelga Violenta, Derecho del Trabajo, Reforma Laboral.

ABSTRACT: In this paper the authors inquire on the notion of strike and its peaceful nature under the framework of the Labor Bill. The objective is to highlight how, once the strike is materialized, and once the trade union freedom with other fundamental rights are weighted, trade union freedom prevails sheltering a series of episodes of conflict and confrontation between trade union and employer, reasoning that under the Labor Bill loses its substance.

Key words: Collective Bargaining, Violent Strike, Employment Law, Labor Bill.

\section{INTRODUCCIÓN.}

Las principales modificaciones legislativas de índole laboral de las últimas décadas han estado marcadas por la presencia de situaciones de conflicto que requieren de una solución normativa urgente. Así por ejemplo, tanto la Ley de Subcontratación Nº 20.123 del año 2006 como la Ley $\mathrm{N}^{\circ} 20.760$ del año 2014 que incorpora el concepto de unidad económica, surgen como respuestas a conflictos de índole laboral que interpelan a la sociedad, procurando mejorar la situación laboral de los trabajadores en el país. En este sentido, las modificaciones legislativas en materia laboral han estado encaminadas a evitar el abuso de poder del empleador en el marco de la relación laboral, regulando el actuar empresarial y estableciendo garantías a favor de los trabajadores, intentando así, lentamente, nivelar el ámbito de la relación laboral.

Siguiendo esta misma línea, el proyecto de ley presentado por el Gobierno de la Presidenta Michelle Bachelet el 29 de diciembre del año 2014, que introduce modificaciones al Código del Trabajo en el ámbito de los derechos colectivo con el objeto de modernizar el

\footnotetext{
* Abogada. Licenciada en Ciencias Jurídicas y Sociales de la Facultad de Derecho, Universidad de Chile. Máster of Laws, University College London. fernandaespinosam@gmail.com

**Abogada. Licenciada en Ciencias Jurídicas y Sociales de la Facultad de Derecho, Universidad de Chile. michiblev@gmail.com
} 
sistema de relaciones laborales, busca incrementar las tasas de sindicalización y fortalecer los sindicatos, entregando más herramientas a la organización sindical en el ámbito de la negociación colectiva, procurando nivelar la fuerza de ambas partes en un proceso que busca, tal como su definición lo señala, "establecer condiciones comunes de trabajo y de remuneraciones" (artículo 303 del Código del Trabajo). Sin embargo, el proyecto de reforma no ha estado exento de debate, recibiendo numerosas críticas tanto de parte de los trabajadores como del empresariado. Si bien el proyecto de ley viene a satisfacer las demandas de los trabajadores y organizaciones sindicales en cuanto a fortalecer a los sindicatos en la negociación colectiva y eliminar una serie de prerrogativas que, de una u otra forma, le otorgaban ciertos niveles de seguridad y estabilidad al empleador en el marco de la negociación colectiva, una de las principales críticas que recibió el texto original de parte de las organizaciones de trabajadores fue la inclusión del término pacífico para caracterizar y definir el derecho a huelga. Correlativamente a ésta propuesta, se pretendió incorporar nuevas causales de desafuero y de prácticas antisindicales, disposiciones recibidas con reticencia por parte del movimiento trabajador, señalándose que estas modificaciones implicaban criminalizar el derecho a huelga. Lo anterior, permite preguntar cómo, en el marco del nuevo proyecto de ley, se pretende solucionar posibles situaciones de conflicto generadas en el marco de una negociación colectiva, en especial, situaciones de violencia y enfrentamiento que pudieran originarse durante la huelga.

El presente trabajo pretende analizar las situaciones de conflicto originadas en un proceso de negociación colectiva, en específico, al momento de desarrollarse la huelga, instancia en la cual se ven enfrentados de forma más extrema los intereses de los trabajadores y sus respectivas organizaciones sindicales, con el empleador y sus propias preocupaciones relacionadas a la estabilidad, la producción y el orden de la empresa. Así, revisaremos primero la situación actual en materia de relaciones colectivas, para luego revisar las modificaciones que el proyecto de ley pretende o bien, pretendía incorporar. Luego, se analizarán los límites del derecho a huelga, así como las situaciones en que este derecho pudiera verse enfrentado a otros derechos fundamentales. Finalmente pasaremos a revisar cuáles son las herramientas que tiene el empleador para enfrentar situaciones de violencia en un contexto de huelga junto a posibles soluciones normativas para evitar o bien resolver estas situaciones sin afectar los derechos fundamentales de los trabajadores individuales o bien, agrupados como organización sindical. Se pretende así proporcionar material a la discusión legislativa laboral del país, en la búsqueda de un marco normativo que facilite y promueva la comunicación entre trabajadores y empleadores, procurando generar procesos de negociación colectiva más rápidos, más sencillos y más pacíficos, acorde con la concepción democrática moderna existente en nuestro país por medio de la cual se logren acuerdos óptimos que satisfagan por igual, a trabajadores y empleadores.

\section{RELACIONES COLECTIVAS EN CHILE: SITUACIÓN ACTUAL}

La negociación colectiva en Chile se encuentra regulada en los artículos 303 y siguientes del Código del Trabajo. Sin embargo, nuestra Constitución Política de la República, es el cuerpo normativo que establece las principales directrices en cuanto a la libertad sindical y al procedimiento de negociación colectiva. En efecto, el artículo $19 \mathrm{~N}^{\circ} 16$, en sus párrafos 4to y 5to, establece que "La negociación colectiva con la empresa en que laboren es un derecho de 
los trabajadores, salvo los casos en que la ley expresamente no permita negociar. La ley establecerá las modalidades de la negociación colectiva y los procedimientos adecuados para lograr en ella una solución justa y pacífica. La ley señalará los casos en que la negociación colectiva deba someterse a arbitraje obligatorio, el que corresponderá a tribunales especiales de expertos cuya organización y atribuciones se establecerán en ella.” Por su parte, el artículo 303 del Código del Ramo lo define como "un procedimiento a través del cual uno o más empleadores se relacionan con una o más organizaciones sindicales o con trabajadores que se unan para tal efecto, o con unos y otros, con el objeto de establecer condiciones comunes de trabajo y de remuneraciones por un tiempo determinado". En la práctica, las características comunes de un proceso de negociación colectiva son la existencia de un procedimiento: a) bipartito (a lo menos); b) reglado, conformado por plazos y etapas que deben cumplirse; c) que involucra una necesaria comunicación o dialogo entre ambas partes; d) mediado o dirigido por la presencia de la Inspección del Trabajo.

Difícil es negar que, actualmente, el proceso de negociación colectiva en Chile dista mucho de ser una instancia de dialogo o comunicación en el cual empleador y organización sindical puedan satisfacer intereses comunes en el marco de una relación laboral o una comunidad empresarial coherente y funcional. Por el contrario, la negociación colectiva es, en muchos casos, el único momento en el cual organización sindical y empleador se enfrentan, intercambio que suele verse cubierto de un clima de inseguridad y desconfianza entre ambas partes, cuestión que se evidencia al observar que no existen en nuestra legislación instancias de comunicación cotidiana entre sindicatos y empresa. En efecto, el ejercicio del derecho de información del sindicato, momento en el cual éste puede informarse del estado financiero de la empresa y de su desarrollo, se presenta solamente en el marco de una negociación colectiva, en los momentos inmediatamente previos al término del contrato o convenio colectivo vigente, y/o bien, antes de la presentación de un nuevo proyecto de instrumento colectivo. Por otra parte, el acotado rol de la Dirección del Trabajo en el proceso de negociación colectiva tampoco contribuye a generar una relación fluida y comunicativa, pues la única instancia en la cual este organismo realmente ejerce un rol mediador o conciliador es durante la etapa de los Buenos Oficios, instancia breve y acotada que se desarrolla al término de lo que fue el proceso de negociación propiamente tal y una vez que esta instancia ha fracasado. Adicionalmente, la posibilidad de contratar trabajadores de reemplazo durante la huelga trae como consecuencia inevitable que dicha instancia del proceso no sea en algunos casos lo suficientemente efectiva. En efecto para algunos académicos, como José Luis Ugarte Cataldo, el reemplazo de trabajadores en huelga afecta gravemente el contenido esencial de este derecho, privándolo en definitiva de toda su eficacia ${ }^{1}$. Así las cosas, no es de extrañar que en ciertas ocasiones el proceso de negociación colectiva, y en concreto, la etapa de huelga de los trabajadores, se torne violenta, siendo ésta, en la práctica, su única herramienta para alcanzar notoriedad y ejercer algún tipo de presión.

\section{PROYECTO DE REFORMA A LA RELACIONES LABORALES}

Analizados brevemente los principales aspectos de la legislación vigente en torno al desarrollo del proceso de negociación colectiva, es preciso pasar a revisar el contenido del

\footnotetext{
${ }^{1}$ CAAmaño y UGarte(2008) p. 92.
} 
proyecto de ley que se encuentra actualmente en tramitación y que modificará la actual normativa que rige el proceso de negociación colectiva.

\subsection{Sobre el proyecto de ley: aspectos generales}

Consta en el Mensaje de la Presidenta de la República N $^{\circ} 1055 / 362$ que dio inicio al proyecto de ley que moderniza el sistema de relaciones laborales, que el fin último de este proyecto consiste en equilibrar la relación entre trabajadores y empleadores. Así se señala que "la existencia y respeto de los derechos colectivos de los trabajadores permite una regulación institucional de las tensiones y conflictos que, naturalmente, se presentan en el ámbito laboral, encauzando su solución conforme a las reglas del derecho y con pleno reconocimiento de los derechos fundamentales de todas las partes. De este modo se evita la proliferación de conflictos inorgánicos que se produce, justamente, cuando los mecanismos institucionales no son los adecuados. El diálogo social en la empresa y, particularmente, la negociación colectiva, son, entonces, esenciales para el crecimiento, productividad y desarrollo de empresas socialmente sustentables. La negociación colectiva es una herramienta de participación, de reconocimiento social de los trabajadores y sus organizaciones sindicales, pero además de administración, porque le permite a las empresas apoyarse en los sindicatos para poner en práctica una gestión satisfactoria de los recursos humanos, lo que favorece finalmente la calidad de los productos que vende o de los servicios que presta y, en general, mejora su productividad"'. Lo anterior se desprende también de las declaraciones vertidas por el Señor Rodrigo Valdés, Ministro de Hacienda, en el informe emitido por la Comisión de Hacienda de fecha 10 de junio del año en curso, al señalar que "el presente proyecto tiene básicamente tres grandes objetivos: reequilibrar la relación entre las partes negociadoras hacia estándares internacionales, predominando el diálogo y la cooperación entre éstas; legitimar el sistema institucional, desarrollar el conflicto al interior de la empresa y permitir que las empresas se puedan adaptar a entornos más competitivos"3.

Pues bien, la intención de promover un proceso de diálogo social sincero, en el cual ambas partes se comuniquen directa y constantemente queda claramente expresada en el proyecto de ley en cuestión, reforma que por un lado, pretende nivelar la fuerza de la organización sindical con la empresa, a través de modificaciones relacionadas principalmente a la titularidad sindical, modificando las materias sujetas a negociación, modificando prerrogativas como la extensión de beneficios y prohibiendo el reemplazo de trabadores en huelga, entre otros; pero que adicionalmente, establece nuevos canales y medios de comunicación y dialogo, constantes y obligatorios para ambas partes.

Así las cosas, en materia de titularidad sindical, la reforma laboral reconoce a los sindicatos como sujeto principal de la negociación colectiva. En consecuencia, en las negociaciones colectivas de empresa, el titular exclusivo de la negociación colectiva será el sindicato, excluyéndose la posibilidad de negociar con grupos de trabajadores, como ocurre hoy en día, a menos que en la empresa no exista una organización sindical. Adicionalmente, en esta misma materia se reconoce a los sindicatos interempresa el derecho a negociar colectivamente cuando tengan un número de afiliados no inferiores a los quórum exigidos a los

\footnotetext{
2 BACHELET (2014).

${ }^{3}$ COMISIÓN DE HACIENDA (2015).
} 
sindicatos de empresa. Esto se traduce en que la negociación colectiva con sindicatos interempresa ya no será voluntaria para el empleador quedando obligado a negociar colectivamente con dichas organizaciones cuando se cumpla con los requisitos de afiliación.

En relación a los derechos y beneficios negociados por el sindicato, los titulares de los beneficios de un instrumento colectivo ya no serán sólo los trabajadores que participaron de la negociación colectiva, si no que estos se extenderán automáticamente a los trabajadores que se afilien al sindicato, aun con posterioridad a la negociación colectiva. Adicionalmente, para extender los beneficios de un contrato colectivo a trabajadores no afiliados al sindicato, será necesario el acuerdo del sindicato, sin el cual la extensión de beneficios del empleador será considerada una práctica antisindical.

Por otra parte, el proyecto propone que la respuesta del empleador contenga, a lo menos, un piso de negociación. Esto significa que en caso de existir un instrumento colectivo vigente, el empleador deberá ofrecer a lo menos idénticas estipulaciones a las establecidas a dicho instrumento colectivo, con los valores que corresponda pagar a la fecha de término del contrato. En caso de no existir contrato colectivo vigente, la propuesta del empleador no podrá contener beneficios inferiores a los que de manera regular y periódica se haya otorgado a los trabajadores de la empresa.

Adicionalmente, y quizás una de las modificaciones propuestas más debatida públicamente, ha sido la prohibición absoluta del reemplazo de los puestos de trabajo de los trabajadores durante el desarrollo de la huelga, ya sea con personal propio de la empresa, o bien por medio de la contratación de trabajadores externos, saldándose así una deuda histórica en materia de libertad sindical. En materia de servicios mínimos, se consagra en el proyecto de ley el deber de la organización sindical de proveer durante la huelga el personal necesario para atenderlos, señalándose que deberá atenderse a los servicios mínimos estrictamente necesarios para proteger los bienes e instalaciones de la empresa y prevenir accidentes, así como garantizar la prestación de servicios de utilidad pública, la atención de necesidades básicas de la población y para garantizar la prevención de daños ambientales o sanitarios.

En lo que respecta a los derechos y deberes de información de la empresa hacia el sindicato, se consigna la obligación de información periódica, ampliándose los deberes de información relativos a la preparación de la negociación colectiva misma. El proyecto en cuestión propone además ampliar las materias de negociación, pudiendo incluir acuerdos para la conciliación del trabajo con las responsabilidades familiares, planes de igualdad de oportunidades y equidad de género en la empresa, acuerdos para la capacitación y reconvención productiva de los trabajadores, constitución y mantenimiento de servicios de bienestar, mecanismos de solución de controversias, entre otros. Adicionalmente, se establece que podrán negociarse acuerdos de extensión de beneficios y sistemas excepcionales de jornada de trabajo y descanso, bancos de horas extras, duración y retribución de jornadas pasivas. Sin embargo, se mantiene la normativa en cuanto a que no serán materias de negociación colectiva aquellas que restrinjan o limiten la facultad del empleador de organizar, dirigir y administrar la empresa y aquellas ajenas a la misma.

Algunas de las modificaciones descritas son, a todas luces, un avance necesario en lo que es la necesaria relación y vinculación que debe existir entre empleadores y trabajadores en pos 
de la creación de una comunidad compleja que ha dado lugar a nociones como la existencia de una ciudadanía empresarial. Al respecto, la OIT ha considerado, dentro de requisitos relacionados al derecho de huelga y su licitud, la obligación de "recurrir a los procedimientos de conciliación, mediación y arbitraje (voluntario) en los conflictos colectivos como condición previa a la declaración de la huelga, en la medida en que sean adecuados, imparciales y rápidos, y que las partes puedan participar en cada etapa"4. Así las cosas, la efectividad de éstas medidas y de la generación de un ambiente laboral claro y transparente requerirá que ambos estamentos decidan trabajar unidos hacia un mejor desarrollo empresarial y económico, aparejado necesariamente de una renovada situación laboral para todos aquellos trabajadores que con su trabajo participan del crecimiento de la empresa y de su consecuente avance financiero.

En virtud de lo anterior, esenciales serán las disposiciones transitorias de la ley una vez terminada su tramitación, las cuales deberán establecer periodos de información y de aplicación de larga data, con el fin de instruir tanto a pequeñas, medianas y grandes empresas sobre sus nuevos deberes, proporcionando a la ciudadanía toda la información relevante a este respecto. En esta tarea, el rol de la Dirección del Trabajo se vuelve esencial, rol que deberá necesariamente modificarse en miras a la imparcialidad y al trabajo en conjunto tanto con trabajadores como con empleadores. Un comportamiento sancionatorio irracional o marcadamente parcial puede no sólo generar sanciones inmanejables sobre todo para pequeñas y medianas empresas, sino que destruir cualquier intento de comunidad laboral en un espacio que debe manejarse con cuidado, buscando sopesar los intereses presentes de ambas partes, y vincularlos a metas y proyectos futuros. Así, el cambio de mirada debe pasar también por los funcionarios de la Dirección del Trabajo, quienes deberán ser capacitados para poder funcionar como mediadores y facilitadores de espacios de comunicación y diálogo, más que campeones designados del trabajador o de la organización sindical.

\subsection{El proyecto de ley y la huelga}

Considerando las nuevas prerrogativas de las organizaciones sindicales, los nuevos deberes de información del empleador y las instancias de mediación adicionales, unidas a la prohibición del reemplazo de trabajadores en huelga, a la nueva titularidad de la organización sindical, a la modificación en torno a la extensión de beneficios, entre otros, no se puede sino generar como contrapartida un marco normativo que pretenda mantener el ánimo de trabajo conjunto y de debate constructivo entre las partes involucradas en un proceso de negociación colectiva.

Así, el proyecto de ley incorporaba inicialmente una definición del derecho a huelga, en virtud del cual se establecía que "La huelga es un derecho que debe ser ejercido colectiva y pacíficamente por los trabajadores" ${ }^{2}$, recogiendo así, ahora a nivel de ley, aquellas características ya existentes a nivel constitucional. Sobre este punto, el debate fue intenso; en efecto en el informe de la Comisión del Trabajo de fecha 3 de junio de 2015, el Sr. Díaz, por ejemplo, afirmó que "Al mencionar el carácter pacífico que debe tener la huelga se deja al arbitrio de la Inspección del Trabajo y los Tribunales el establecimiento de la determinación de lo que se entiende por 'huelga pacífica'. En opinión del expositor, es evidente que si se circunscribe la huelga a aquellos actos de simple manifestación (cantos y ruidos) pierde gran

\footnotetext{
${ }^{4}$ INTERNATIONAL LABOUR OFFICE (2015). p. 26.

${ }^{5}$ BACHELET (2014) p. 349.
} 
fuerza para los trabajadores que en la actualidad buscan, por ejemplo, bloquear la entrada a la empresa e impedir su funcionamiento por diversos medios para provocar un real impacto en el negocio. En este sentido, la Coordinadora de Sindicatos del Comercio manifestó su preocupación respecto a la eventual persecución de los trabajadores en huelga por sus actos cuando no sean considerados pacíficos, sin que la ley establezca límites claros a dicha disposición" ". El Sr. Ensignia, por su parte, indicó que "En primer lugar, la denominación de "pacífico" del proceso de negociación colectiva y la referencia a eventuales actos de violencia puede abrir interpretaciones administrativas y judiciales que lo limiten severamente y dé lugar a persecuciones al sindicalismo en nombre de actitudes 'no pacíficas', por lo que no debiera incorporarse a la legislación"' . El Sr. Mesina, a su vez, afirmó lamentar "la 'criminalización' de la huelga, nuevamente en atención a que no se comprende la naturaleza misma de dicha forma de presión, especialmente la norma que califica la huelga como 'pacífica" "8. La Presidenta de la CUT, por su lado, planteó la modificación de la definición de la huelga que propone el proyecto, eliminando la utilización del concepto pacífica. El señor Moro, en representación de la Vicaría, manifestó "su preocupación con algunos aspectos del proyecto que aparecen poco objetivables, como los conceptos de huelga pacífica y huelga violenta" ". Por otro lado, el Sr. Menares señaló que "se aprecia que la calificación de la huelga como 'pacífica' corresponde a un claro aspecto regresivo de la reforma, adoptando una concepción de huelga que no comprende la naturaleza misma de forma de presión" ${ }^{10}$. Terminado el citado debate, las nuevas indicaciones del Ejecutivo propusieron sustituir la expresión "colectiva y pacíficamente", por la palabra "colectivamente", indicación que sometida a votación, se aprobó por 7 votos a favor, 4 en contra y 0 abstenciones. Así, en virtud de la redacción final del artículo 347, "la huelga es un derecho que debe ser ejercido colectivamente por los trabajadores".

Junto a lo anterior, el proyecto de ley proponía inicialmente incorporar una nueva práctica antisindical o desleal de la organización sindical, en virtud de la cual incurrirían en práctica antisindical los trabajadores, las organizaciones sindicales o el empleador que realizara acciones que entorpecieran la negociación colectiva o sus procedimientos, entre las cuales se encontraba: "b) El ejercicio de fuerza física en las cosas, o física o moral en las personas durante el procedimiento de negociación colectiva, especialmente si obstaculizara el ingreso para prestar servicios del personal directivo y de trabajadores no involucrados en la huelga" 11 . Igualmente, se propuso la incorporación en el artículo 290 de nuevas prácticas desleales en contra de la libertad sindical, las cuales serían "f) El que utilizare los derechos sindicales o fueros que establece este Código, de mala fe o con abuso del derecho; y g) El que ejerciere fuerza física en las cosas, o física o moral en las personas con ocasión del ejercicio de la actividad sindical" ${ }^{\prime 2}$. En relación a estas conductas, se propuso incorporar un inciso nuevo al artículo 292, el cual indicaba que "Tratándose de la práctica desleal a que se refiere el literal g) del artículo 290, sin perjuicio de las multas establecidas en el inciso primero, el dirigente

\footnotetext{
${ }^{6}$ COMISIÓN DEL Trabajo (2015) p. 4.

${ }^{7}$ COMISIÓN DEL TRABAJO (2015) p. 117.

${ }^{8}$ COMISIÓN DEL TRABAjO (2015) p. 131.

${ }^{9}$ Comisión del Trabajo (2015) p. 115.

${ }^{10}$ Comisión del Trabajo (2015) p. 113.

${ }^{11}$ BACHELET (2014) p. 29.

12 BACHELET (2014) p. 72.
} 
sindical que incurriere en ella podrá, atendida la gravedad de la infracción, ser sancionado con la pérdida del fuero sindical" 13 .

La discusión en torno a la procedencia de las prácticas antisindicales que se buscaba incorporar y a la causal de desafuero relacionada, consta en el Informe de la Comisión del Trabajo de fecha 3 de junio de 2015, en el cual el Sr. Alvear afirma que "contribuye al respeto de los derechos de los demás trabajadores y de la empresa, el que se establezca que ejercer fuerza física en las cosas, o física o moral en las personas con ocasión del ejercicio de la actividad sindical, y utilizar los derechos sindicales o fueros que establece este Código, de mala fe o con abuso del derecho, son prácticas desleales que deben ser sancionadas con multas y que pueden acarrear la pérdida del fuero sindical" 14 . Contrariando lo anterior, el Sr. Steilen sugirió "eliminar la letra g) del artículo 290 propuesto, en la medida en que aquello que allí se considera como práctica desleal del trabajador, a saber, ejercer fuerza física contra las cosas o fuerza física o moral en contra de las personas, implicaría establecer una criminalización del movimiento sindical, especialmente considerando la amplitud del concepto" 15 . Coincidentemente, el señor Díaz manifestó rechazar tajantemente la penalización del derecho a manifestación, mediante la incorporación de la práctica de '(...) el que ejerciese fuerza física en las cosas, o física o moral sobre las personas con ocasión del ejercicio de la actividad sindical', así como el establecimiento del desafuero como sanción a dicha conducta, pues en su opinión implican, "la posibilidad de criminalizar el ejercicio del legítimo de derecho a manifestación. En la actualidad, la ley establece el 'ejercicio de vías de hecho' sobre las personas o las cosas como causal de despido. En el caso de un trabajador aforado, el desafuero es un paso para ejercer dicha causal"16. Adicionalmente, afirma que "la incorporación del concepto de 'fuerza moral' implica un amplio espacio a la arbitrariedad y su incorporación como práctica desleal implica sancionar a la organización sindical en base a actos que son responsabilidad individual de sus miembros" ", razón por la cual manifiesta "rechazar dicha disposición, creyendo que constituye un severo retroceso en el ejercicio de las libertades de expresión y de manifestación, atentando gravemente a la actividad sindical" 18 . Siguiendo una línea similar, el señor Ortega indicó "que el proyecto retrocede en materia de criminalización de la acción sindical. Lo anterior se manifiesta en la adición de un nuevo caso de practica antisindical o desleal al que 'ejerciere fuerza física en las cosas, o física o moral en las personas con ocasión de la actividad sindical'. Con ello, se corre el riesgo de penalizar la acción sindical, la cual naturalmente contempla alguna forma de presión física o moral para generar efectos" ${ }^{\prime 19}$. En cuanto al desafuero, el señor Menares afirmó que era "preocupante las nuevas normas relativas a desafuero, las cuales calificó de ambiguas y entregadas a la interpretación de la autoridad administrativa y judicial" 20 .

Sin embargo, tras las primeras discusiones del proyecto de ley y luego de las indicaciones efectuadas por el Ejecutivo, las conductas de dicho artículo, ahora, artículo 408, fueron acotadas a las siguientes: "a) La ejecución durante el proceso de la negociación colectiva de

\footnotetext{
13 BACHELET (2014) p. 72.

14 COMISIÓN DEL TRABAJO (2015) p. 30.

${ }^{15}$ COMISIÓN DEL TRABAJO (2015) p. 35.

${ }^{16}$ COMISIÓN DEL TRABAJO (2015) p. 38.

${ }^{17}$ COMISIÓN DEL TRABAJO (2015) p. 38.

${ }^{18}$ COMISIÓN DEL TRABAJO (2015) p. 38.

${ }^{19}$ COMISIÓN DEL TRABAJO (2015) p. 61.

${ }^{20}$ COMISIÓN DEL TRABAJO (2015) p. 113.
} 
acciones que impliquen una vulneración al principio de buena fe que afecte el normal desarrollo de la misma; b) El acuerdo para la ejecución de prácticas atentatorias contra la negociación colectiva y sus procedimientos, en conformidad a las disposiciones precedentes, y los que presionen física o moralmente al empleador para inducirlo a ejecutar tales actos; c) La divulgación a terceros ajenos a la negociación de los documentos o la información recibida del empleador y que tengan el carácter de confidencial o reservada; d) El incumplimiento del deber de proveer el o los equipos de emergencia que fueron concordados por las partes o dispuestos por la autoridad competente, según corresponda" ${ }^{21}$. Así, nuevamente tras las indicaciones se elimina la conducta que hacía relación a una negociación sindical pacífica. En cuanto la regulación de prácticas desleales contra la libertad sindical, el artículo 290 del proyecto de ley actual pasó a incorporar solamente una de las conductas propuestas en el proyecto de ley original, a saber "f) Utilizar los derechos sindicales o fueros que establece este Código, de mala fe o con abuso del derecho" 22 , eliminándose entonces la conducta relacionada con el uso de fuerza física o moral. De igual forma cabe señalar que las indicaciones del Ejecutivo propusieron eliminar el inciso que decía relación con la procedencia del desafuero en relación con la conducta de práctica antisindical referida al uso de la fuerza.

La eliminación de los artículos descritos demuestra una actitud contradictoria y preocupante. Por un lado, se genera la falsa impresión de que no existe en nuestra actual legislación referencia alguna a directrices generales de huelga pacífica, las cuales están expresamente consagradas en nuestro cuerpo constitucional. Adicionalmente, atendiendo a los argumentos descritos expresados durante la discusión de los artículos en cuestión, discusión que concluyó con la eliminación de la referencia legal a una huelga desarrollada de manera pacífica, junto a las conductas descritas inicialmente propuestas como constitutivas de prácticas antisindicales, fácil es concluir equivocadamente que nuestro legislador comparte en cierto sentido la creencia de que la libertad sindical y el desarrollo de una negociación colectiva, como medida de presión efectiva, requiere necesariamente el uso de medios de presión que pueden, en su esencia, comprender actos de violencia y agresión. Esta conclusión no sólo atenta contra todo concepto de derecho fundamental y la necesaria ponderación y proporcionalidad que debería hacerse, ponderación que debe siempre velar por el núcleo esencial de los derechos fundamentales en pugna, sino que parece además permitir un comportamiento que, en su posición más extrema, es contrario a los pilares de una sociedad democrática en la cual debe primar el diálogo, la comunicación constructiva, y la buena fe, acorde con las directrices que la misma OIT ha recogido y recomendado ${ }^{23}$. En este sentido, dicho organismo es claro al hablar y amparar las huelgas legítimas, entendiendo como tales aquellas que se desarrollan en condiciones lícitas y razonables, indicando el Comité de Libertad Sindical que "los principios de la libertad sindical no protegen extralimitaciones en el ejercicio del derecho de huelga que consistan en acciones de carácter delictivo" 24 . Al respecto, se habla comúnmente de la "extralimitación en el ejercicio de la huelga", afirmándose que éstas "revisten formas variadas, que van desde la participación de categorías de trabajadores privados legítimamente de este derecho o el incumplimiento de requisitos razonables para declarar la huelga hasta el deterioro o destrucción de bienes y locales de la empresa y la violencia física contra personas" 25 .

\footnotetext{
${ }^{21}$ COMISIÓN DEL TRABAJO (2015) p. 218.

22 COMISIÓN DEL TRABAJO (2015) p. 318.

23 INTERNATIONAL LABOUR OFFICE (2015) p. 8.

24 OFICINA INTERNACIONAL DEL TRABAJO GINEBRA (2000) p. 44.

25 OFICINA INTERNACIONAL DEL TRABAJO GINEBRA (2000) p. 44.
} 
Pues bien, si en un contexto normativo desigual e inequitativo podía inicialmente llegar a entenderse el uso de la fuerza física en contra de la propiedad o incluso, de las personas, las modificaciones que se incorporan a través de éste proyecto de ley equilibran notoriamente las posiciones de empleadores y trabajadores en el ámbito colectivo, volviéndose inexplicable e injustificable la incorporación y uso de cualquier tipo de violencia en un contexto de negociación en el cual deberá siempre propenderse a alcanzar una comunicación y posterior acuerdo pacífico y ecuánime.

\section{EL DERECHO DE LOS TRABAJADORES A MANIFESTARSE PACÍFICAMENTE: DERECHO A HUELGA}

Durante el último tiempo, tras el despertar ciudadano que gatilló el surgimiento de nuevos y múltiples movimientos y organizaciones sociales, se han multiplicado a su vez los episodios de violencia ciudadana al momento de manifestarse públicamente las nuevas exigencias que se hacen al Estado. Así, sin timidez alguna, las organizaciones expresan de forma pública su malestar actual y sus correlativos intereses y deseos, situación que se ve reflejada también en espacios públicos y privados en el marco de procesos de negociación colectiva, y en particular, en las instancias de huelga. Así, se pudo ver, con ocasión de la huelga de la Empresa de Transportes Express-Alsacia, como los trabajadores huelguistas destruyeron bienes de su empleador e impidieron mediante la fuerza el ingreso de otros trabajadores a las dependencias de la empresa, paralizándose parte del servicio de transporte de la Región Metropolitana, servicio público esencial para el funcionamiento de la misma, e incluso interviniéndose el medio de transporte hermano, Metro de Santiago, hecho que afectó a miles de personas. Si bien en nuestro país el número de huelgas de carácter violento siguen siendo inferiores al ejercicio pacífico de este derecho, preocupa que con el proyecto de reforma que se encuentra en tramitación, aumenten de forma desmedida las situaciones de conflicto y de violencia, afectándose no sólo el normal desarrollo de nuestra sociedad, sino que atentándose contra el espíritu u objetivo mismo de la negociación colectiva, en virtud del cual ambas partes deben dialogar buscando en conjunto un acuerdo que permita mejorar la situación de los trabajadores sin que ello signifique un daño irreparable para la empresa.

A diferencia de lo que ocurre en otros países, no se consagra legalmente de forma expresa que la huelga deba ejercerse de forma pacífica. En efecto, como señalamos precedentemente, el proyecto original de reforma laboral presentado por el ejecutivo contemplaba la inclusión de esta mención, señalándose que "la huelga es un derecho que debe ser ejercido colectiva y pacíficamente por los trabajadores", situación que generó debate y críticas de parte de quienes estimaban que se criminalizaba del derecho a huelga, argumentándose principalmente en base a la actual incertidumbre conceptual y posterior calificación que luego debía hacerse en torno al término pacífico.

En este contexto, cabe preguntarse si nuestra legislación permite de alguna forma los actos de violencia con ocasión del ejercicio del derecho a huelga, o bien, si por el contrario este derecho debe necesariamente ser ejercido de forma pacífica por las organizaciones sindicales. Pues bien, aun considerando que tras las primeras indicaciones del ejecutivo efectuadas al proyecto de reforma se eliminó el término "pacifico" para describir el derecho a huelga, debería de existir consenso en que este derecho legítimo de los trabajadores no puede ser ejercido de forma violenta, consideración acorde con nuestro cuerpo constitucional. Lo 
contrario, implicaría erradamente sostener que hay un nivel mínimo pero que puede o incluso debe ser tolerado en el ejercicio de la libertad sindical.

\subsection{La huelga como un derecho fundamental}

Si bien, nuestro sistema constitucional no consagra de forma manifiesta el derecho a huelga, este derecho se encuentra reconocido de forma implícita en nuestra Constitución Política de la República ${ }^{26}$, al garantizar y reconocer la libertad sindical y autonomía colectiva en su artículo 19 números 16 y 19. Asimismo, el derecho a huelga ha sido reconocido como derecho fundamental en diversos tratados de carácter internacional ratificados por Chile, tales como en el Pacto Internacional de Derechos Económicos, Sociales y Culturales ${ }^{27}$ y la Convención Americana sobre Derechos Humanos ${ }^{28}$. Por su parte, el Convenio $N^{\circ} 87$ de la Organización Internacional del Trabajo (OIT), vigente en Chile desde el año 2000, reconoce en sus artículos $3^{\circ}$ y $10^{\circ}$ el derecho a huelga como una manifestación de la libertad sindical.

La libertad sindical puede definirse como "el derecho que asiste a los trabajadores para constituir organizaciones, afiliarse o desafiliarse a ellas, a darse su propia normativa sin intervención de terceros y, especialmente, el derecho al ejercicio de la actividad sindical por medio de aquellas acciones tendientes a la defensa y promoción de los intereses que le son propios, en particular, la negociación colectiva y el derecho a huelga" 29 . En relación a este importante concepto, es preciso indicar que su incorporación y reconocimiento normativo y jurisprudencial se encuentra necesariamente vinculado al reconocimiento de los derechos sociales, por un lado, y a su vez, por "la aceptación de derechos cuyo titular no es el individuo, sino que un conjunto de personas" ${ }^{30}$. En virtud de lo anterior, necesario es distinguir su contenido esencial, por un lado, el derecho de sindicación (faz orgánica) y el derecho a hacer valer los intereses colectivos de los trabajadores organizados, mediante la acción reivindicativa y participativa, lo que se canaliza a través del ejercicio de los derechos de negociación colectiva y de huelga (faz funcional) ${ }^{31}$.

Por otra parte, en Chile el derecho a huelga ha sido expresamente reconocido y regulado con ocasión del proceso de negociación colectiva reglada, pese a que para algunos autores nacionales, esto constituye de por sí una restricción y afectación de este derecho ${ }^{32}$. En efecto, sólo en el marco de dicho proceso la huelga será considerada "legal", por lo que a contrario sensu, debemos entender que toda aquella huelga que se dé sin sujeción estricta a las normas establecidas en el Código del Trabajo carecerá de la protección constitucional implícita proporcionada. Sin embargo, que el derecho a huelga se encuentre reconocido como derecho fundamental en nuestra Constitución Política y consagrado expresamente en nuestro ordenamiento jurídico, no significa que éste derecho no esté afecto a limitaciones o restricciones. En efecto, el derecho a huelga no puede en ningún caso ser absoluto, debiendo

\footnotetext{
${ }^{26}$ CAAMAÑO Y UGARTE (2008) p. 79

27 PaCto de Derechos Económicos, Sociales y Culturales, Artículo 8 Nº 2.

${ }^{28}$ CONVENCIÓN Americana De Derechos Humanos Artículo 8.1 Letra D.)

${ }^{29}$ VARAS (2003) p. 3.

30 GAMONAL (2002) p. 87.

${ }^{31}$ VARAS (2003) p. 3; CAAMAÑO (2008) pp. 265-291.

32 CAAMAÑO Y UGARTE (2008) p. 78.
} 
estar restringido en función de la protección de otros bienes jurídicos de similar relevancia, o bien, los derechos fundamentales de terceros.

Si bien la mayoría de la doctrina concuerda en que la relevancia del derecho a huelga reside en la posibilidad que otorga a los trabajadores de protestar y manifestarse contra el empleador con el objeto de obtener mejores condiciones laborales y propender a la búsqueda de un equilibrio de fuerzas entre partes, no debemos olvidar que la huelga es en definitiva una medida extrema de presión ${ }^{33}$. La huelga, en efecto, debe siempre ser considerada como un derecho o medida de última ratio, es decir, ésta debiera ocurrir una vez que se han agotados todas las posibilidades de negociación, o bien, cuando estas definitivamente han fracasado y por tanto los trabajadores carecen de otras alternativas. Al respecto el Comité de Libertad Sindical de la Organización Internacional de Trabajo (OIT), ha señalado que "Los principios de la libertad sindical no protegen extralimitaciones en el ejercicio del derecho de huelga que consistan en acciones de carácter delictivo. No deberían imponerse sanciones penales por actos de huelga, salvo en los casos en que no se respeten las prohibiciones relativas a la huelga que estén en conformidad con los principios de la libertad sindical. Cualquier sanción impuesta por actividades ilegítimas relacionadas con huelgas debería ser proporcional al delito o falta cometida, y las autoridades deberían excluir el recurso a medidas de encarcelamiento contra quienes organizan o participan en una huelga pacífica" ${ }^{34}$, recalcando así, que la protección de la libertad sindical y consecuentemente de la huelga, sólo se mantendrá en la medida que estos derechos se ejerzan de forma pacífica y sin extralimitaciones.

Por otra parte, si bien el Código del Trabajo no dispone limitaciones particulares al derecho a huelga, no debemos olvidar que todo derecho debe sujetarse al respeto a la moral, el orden público y al bien común. En efecto, como bien ha señalado la Dirección del Trabajo, "los derechos fundamentales no son ilimitados o absolutos, reconocen como una consecuencia necesaria de la unidad de interpretación del ordenamiento constitucional ciertos límites a su ejercicio; límites que inexcusablemente deben fundarse en la protección de otros derechos o bienes constitucionales, la moral, el orden público y el bien común, y que hacen conveniente o justificable la imposición de restricciones al derecho fundamental. Ningún derecho fundamental puede ser interpretado en sí mismo, sino que mediante una visión sistémica que tome en cuenta el significado de cada una de las garantías constitucionales como partes de un sistema unitario. De esta forma, todo derecho, en razón de su naturaleza limitada, debe ceder en su virtualidad protectora para armonizarse y compatibilizarse con otros bienes y derechos, también de relevancia constitucional" 35 . Por tanto no cabe duda que el derecho a huelga, así como cualquier otro derecho fundamental, debe ejercerse de forma regulada y no librada a la arbitrariedad, en este caso de trabajadores o de las organizaciones sindicales.

La legitimidad de la huelga como mecanismo válido de presión no puede justificar ni amparar situaciones de violencia o de vulneración de otros derechos fundamentales. En este sentido se requiere ser categóricos en cuanto a que no habría fin alguno que legitime el uso de la violencia en un proceso de negociación colectiva, resultando de toda lógica que si la huelga infringe y sobrepasa ciertos límites, deberá entonces perder la protección que la ley y la constitución le garantizan. En efecto en países como Francia o Italia se ha desarrollado

\footnotetext{
${ }^{33}$ HUMERES (2012) pp. 146-162

34 OFICINA INTERNACIONAL DEL TRABAJO (2006) p. 142

35 DIRECCIÓN DEL TRABAJO (2008).
} 
jurisprudencialmente la idea de huelga ilícita o abusiva, como la huelga político partidista o las huelgas que dañan la productividad. Lo anterior es especialmente relevante al considerar que existen escasas herramientas de protección al empleador en aquellos casos en que la huelga se torna violenta, pudiendo sólo acceder a las medidas ordinarias y generales que ofrece nuestro ordenamiento.

\subsection{El ejercicio del derecho a huelga y la colisión de derechos fundamentales}

Nos hemos referido ya a la importancia del derecho a huelga, a su legitimidad dentro del proceso de negociación colectiva y a sus limitaciones. Pero que ocurre cuando este mecanismo legítimo de presión y/o protesta de los trabajadores excede de sus límites y es utilizado de forma violenta afectando derechos fundamentales de otros trabajadores o bien, del empleador. Esto ocurriría, por ejemplo, cuando la huelga de los trabajadores que se encuentran negociando colectivamente afecta bienes del empleador, derechos fundamentales de otros trabajadores o incluso servicios de carácter público, con la consecuente afectación de terceros, incluso ajenos al proceso de negociación colectiva.

En estos casos es innegable que la huelga excede del margen normal o aceptable de presión hacia el empleador, produciéndose una colisión de derechos a ser protegidos. Así, estaremos frente a un enfrentamiento de derechos fundamentales cuando "una conducta amparada por el espacio delimitado de un derecho colisiona con el conjunto de facultades o garantías protegidas - delimitadas - de otro derecho"36. En este caso, se verán contrapuestos, por una parte el legítimo derecho de los trabajadores de manifestarse y protestar por medio de la huelga, ejerciendo así el derecho constitucional de la libertad sindical, y por otra parte el derecho de propiedad del dueño de la empresa, la libertad de trabajo o incluso la integridad física de otros trabajadores. Es relevante señalar que la doctrina constitucional ha afirmado que los derechos fundamentales no son ni absolutos ni ilimitados, encontrándose estructurados de forma tal que es posible distinguir en ellos un espacio delimitado en virtud del cual se puede observar el ámbito máximo de extensión del derecho. Lo anterior permite distinguir en cada uno de los derechos fundamentales un contenido esencial que bajo ninguna circunstancia puede ser afectado, y por otra parte, un espacio delimitado donde es posible imponer ciertas restricciones ${ }^{37}$.

Cabe señalar, que nuestro ordenamiento jurídico entrega a todo empleador el denominado 'poder de dirección', que se traduce en un cúmulo de prerrogativas organizacionales cuyo fundamento se encuentra en las garantías constitucionales de la libertad de la empresa y el derecho de propiedad, establecidas en el artículo 19 números 21 y 24 de la Constitución Política de la República. Por otra parte nos encontraremos con el derecho a la libertad sindical, derecho fundamental ampliamente reconocido y protegido constitucionalmente, por lo que en caso de adoptarse medidas drásticas o muy restrictivas al derecho a huelga, que es una de sus manifestaciones, podría verse afectado. En efecto, la libertad sindical es un derecho de especial relevancia, considerado por la OIT como una de las principales salvaguardias de la paz y de la justicia social. Por tanto, considerando que el poder de dirección del empleador, es una manifestación de un derecho constitucional, al igual que el

\footnotetext{
${ }^{36}$ DIRECCIÓN DEL TRABAJO (2008).

${ }^{37}$ DIRECCIÓN DEL TRABAJO (2008).
} 
derecho a huelga lo es de la libertad sindical, no es posible sostener que el derecho a huelga tenga alguna clases de jerarquía por sobre las garantías fundamentales de que goza el empleador ${ }^{38}$.

Si bien en una organización ideal, trabajadores y empleador deberían ser capaces de trabajar en conjunto para el logro de fines comunes y no contrapuestos, es inevitable que se generen roces entre el poder de dirección del empleador y los derechos fundamentales de los trabajadores, en la búsqueda de un mecanismo adecuado que satisfaga los diversos intereses y necesidades de los distintos estamentos de una empresa. En el ámbito colectivo, estos conflictos se revelarán al intentar conciliar por una parte el interés de empleadores de propender al crecimiento y/o viabilidad de la empresa y por otra parte, el ejercicio de la actividad sindical que busca presionar al empleador con el objeto de obtener mejores remuneraciones y condiciones de trabajo. Adicionalmente, la libertad de trabajo, también podría verse afectada en aquellos casos en que mediante el uso de la fuerza, los trabajadores en huelga impiden el acceso de trabajadores no huelguistas a las dependencias de la empresa. Al respecto el Comité de Libertad Sindical reconoce el principio de la libertad de trabajo de los no huelguistas $^{39}$ y la Comisión de Expertos ha señalado, al tratar de los piquetes de huelga, que estos deben ser pacíficos y que no deben dar lugar a actos de violencia contra personas ${ }^{40}$.

Entonces, cabe preguntarse ¿cómo debe manejarse una situación en la cual estos distintos derechos fundamentales entran en conflicto? Al respecto, tanto la Inspección del Trabajo como los Tribunales de Justicia han señalado que al buscar imponer límites a ciertos derechos fundamentales tras la ponderación realizada entre las garantías afectadas, se debe realizar un examen de admisibilidad y valoración en base al principio de proporcionalidad, que analice la restricción que se pretende adoptar, el medio empleado, la constricción del derecho fundamental, el fin deseado y el ejercicio del propio derecho. Así, este análisis debe incluir la aplicación de los siguientes principios:

1) Principio de adecuación: en virtud del cual, el medio empleado debe ser idóneo para la consecución del fin propuesto, resultando inadecuada en consecuencia, la limitación de un derecho fundamental que no logra proteger una garantía constitucional.

2) Principio de necesidad: el cual exige que la medida limitativa sea la única capaz de obtener el fin perseguido de forma tal que no exista otra forma de alcanzar dicho objetivo sin restringir el derecho, o bien, que no exista otra forma menos gravosa de lograrlo.

3) Principio de proporcionalidad en sentido estricto: en virtud del cual se analiza si la medida que se busca implementar resulta razonable en relación al fin que se desea y a la importancia del derecho fundamental que se busca restringir.

Así las cosas, y en palabras de la Dirección del Trabajo, "se deberá responder asertivamente a las tres reglas o juicios que emanan del principio de proporcionalidad ya referido, consignándose que la falta de fundamentación de la actuación del empleador que lesiona uno o más derechos fundamentales o su desproporción, serán señal inequívoca de lesión ilegítima de derecho fundamental" ${ }^{41}$.

\footnotetext{
${ }^{38}$ SIERRA (2010) pp. 101-113

39 ORGANIZACIÓN INTERNACIONAL DEL TRABAJO(1996) p. 586

${ }^{40}$ ORGANIZACIÓN INTERNACIONAL DEL TRABAJO (1994) p. 174.

${ }^{41}$ DIRECCIÓN DEL TRABAJO (2008)
} 
Pues bien este mismo examen debería utilizarse por nuestros Tribunales de Justicia para determinar si actos de los trabajadores, como podría ser el ejercicio violento de la huelga, afectan o no derechos fundamentales del empleador o de otros trabajadores. Así lo han señalado los Tribunales de Justicia, al advertir que "en el caso de autos, se confrontan dos bienes jurídicos protegidos por el legislador, por un lado, el poder de dirección que detenta el empleador, y por otra, el fuero sindical que corresponde a una norma de tutela de la actividad sindical y consecuentemente, de la libertad sindical, la cual constituye un estado jurídico de excepción que ampara al representante sindical" ${ }^{42}$. La necesaria valoración del derecho a huelga y de sus límites, utilizando los principios de ponderación y proporcionalidad permitirá no incurrir en el error de calificar como violentas situaciones de conflicto que no deban ser catalogadas como tal. Así, un simple intercambio de palabras, o reacciones de inconformidad e indignidad, no podrán ser concebidas como actos de violencia. Al respecto el Comité de Libertad Sindical del Consejo de Administración de la OIT, ha señalado claramente que "el solo hecho de participar en un piquete de huelga y de incitar abierta, pero pacíficamente, a los demás trabajadores a no ocupar sus puestos de trabajo no puede ser considerado como acción ilegítima. Pero es muy diferente cuando el piquete de huelga va acompañado de violencias o de obstáculos a la libertad de trabajo por intimidación a los no huelguistas, actos que en muchos países son castigados por la ley penal" ${ }^{\prime 3}$.

\subsection{Medidas a adoptar frente a actos de violencia durante la huelga}

Los actos de violencia más comunes producidos durante la huelga son la destrucción de bienes de propiedad del empleador y la prohibición de ingreso a la faena mediante la fuerza a otros trabajadores que no son parte de la negociación. Nuestra legislación, a diferencia de lo que ocurre en otros países no contempla sanciones especificas frente a estos u otros actos de violencia durante la huelga, por lo que en caso que actos de esta naturaleza ocurran, regirán las normas generales establecidas en nuestro ordenamiento jurídico. Si bien en caso de actos de violencia durante la huelga, quien vea sus derechos lesionados y dependiendo del tipo de lesión, en teoría tiene diversos medios a través de los cuales poder accionar en contra de quien sea el actor de la acción lesiva, la realidad es que la mayoría de las veces estas medidas son insuficientes y en su mayoría apuntan a intentar frenar o castigar los actos de violencia una vez ocurridos, pero no a prevenir o desincentivar su ocurrencia. En efecto, cuando se producen estas situaciones de violencia la primera medida que usualmente adopta el empleador es solicitar el auxilio de la fuerza pública. Sin embargo, bien es sabido que en muchas ocasiones la llegada de carabineros no hace más que azuzar el enfrentamiento, pudiendo lesionarse a todo aquel involucrado.

Un primer camino legal parece ser el Recurso de Protección, herramienta usual a utilizarse ante bloqueos de entradas correspondientes al lugar de trabajo, o tomas del lugar de trabajo mediante la fuerza. El empleador afectado podrá interponer un Recurso de Protección ante la Ilustrísima Corte de Apelaciones competente, con el objeto de suspender el acto ilegal y arbitrario. Sin embargo, la realidad de los hechos indica que esta medida es la mayoría de las

\footnotetext{
42 SOCIEDAD EDUCACIONAL S AN MIGUEL LIMITADA CON LUIS S ANTIBÁÑEZ V ARGAS (2014).
}

43 OFICINA INTERNACIONAL DEL TRABAJO (2006) p. 651 
veces insuficiente, ya que generalmente tarda mucho en obtenerse siendo en definitiva infructuosa.

Un segundo camino a seguir podría ser la interposición de querellas criminales presentadas contra trabajadores que han participado en hechos de violencia relacionados con huelgas, las que raramente resultan en sentencias condenatoria para los implicados, terminando la mayoría de estas causas sobreseídas por falta de antecedentes, debiendo el empleador resignarse a sobrellevar estas situaciones, además de tener que soportar muchas veces, las millonarias pérdidas económicas con ocasión de la destrucción de bienes de la empresa. Siguiendo la línea anterior, podemos hacer una breve referencia al criticado artículo 11 de la Ley $\mathrm{N}^{\circ} 12.597$ sobre Seguridad Interior del Estado, el cual dispone que: "Toda interrupción o suspensión colectiva, paro o huelga de los servicios públicos o de utilidad pública, o en las actividades de la producción, del transporte o del comercio, producido sin sujeción a las leyes y que produzcan alteraciones del orden público o perturbaciones en los servicios de utilidad pública o de funcionamiento legal obligatorio o daño a cualquiera de las industrias vitales, constituye delito y será castigado con presidio o relegación menores en sus grados mínimo a medio", la que tampoco ha resultado ser una medida efectiva. Lo anterior, pues dado lo controversial de dicha disposición ${ }^{44}$, la realidad es que desde el retorno a la democracia la aplicación de ésta disposición rara vez se efectúa, pudiendo observarse su uso en casos específicos relacionados con la paralización del sistema de transporte, sin que hayan resultado en definitiva trabajadores sancionados por los actos imputados.

En tercer lugar, cabe revisar los caminos establecidos en la normativa laboral, de los cuales la primera posibilidad que tiene el empleador es solicitar a los Juzgados Laborales el desafuero de trabajadores con ocasión de actos de violencia protagonizados durante la huelga. $\mathrm{Al}$ respecto, cabe señalar que, en primer lugar, en un contexto de huelga como parte de una negociación colectiva, la actividad probatoria será especialmente difícil, debiendo ser capaz la parte demandante de identificar a los dirigentes sindicales agresores y relacionarlos sin duda alguna y de forma directa con el hecho violento y el daño causado ${ }^{45}$, carga compleja y difícil. Lo anterior, considerando que "el fuero sindical es una de las más importantes formas de tutelar la libertad sindical, toda vez que la protección que se intenta por medio del fuero es posibilitar la absoluta libertad de los trabajadores en el ejercicio de sus derechos sindicales, frente a cualquier represalia por parte del empleador, en especial el despido, tutela que debe comprender a todos los actos o actuaciones que causen algún tipo de perjuicio a dicha actividad, permitiendo la mantención y vigencia efectiva del contrato de trabajo del aforado, y tal es así, que en Chile se han ratificado los Convenios 98, sobre Derecho de Sindicación y Negociación Colectiva, y 135, sobre representantes de los trabajadores, de la Organización Internacional del Trabajo, que establecen que los trabajadores deben gozar de la adecuada protección contra todo acto de discriminación tendiente a menoscabar su libertad sindical en relación con su empleo, ya sea que el empleador despida o perjudique al trabajador en cualquier forma a causa de su afiliación sindical o de su participación en actividades sindicales" $"$.

\footnotetext{
${ }^{44}$ CAAMAÑO Y UGARTE (2008) p. 86

${ }^{45}$ Express de Santiago con Salinas (2014).

${ }^{46}$ Comercializadora de Frutas Bagno S.A. con Esteban Segundo Villegas Méndez (2014).
} 
Adicionalmente, la interpretación que realizan los Tribunales de Justicia ha incorporado, como parte del ejercicio de la libertad sindical, el uso de la fuerza, tanto física como moral, por lo cual raro es ver una sentencia que conceda, por vías de hecho, un desafuero sindical. En efecto, así se ha pronunciado la Corte de Apelaciones de Santiago, al afirmar el Ministro Astudillo en una prevención que profundiza el razonamiento en torno al rechazo del recurso, que "quien previene considera que tampoco concurre ese imperativo de relevancia o de influencia, porque -como quiera que haya sido- se pretende el desafuero de una dirigente sindical atribuyéndole intervención en una paralización 'ilegal' de actividades. Lo primero que cabe consignar es que si ello fuera cierto, significaría que se está en presencia de una participación que es propia a su condición de representante de los trabajadores, lo que importa alguna forma de contrasentido. No puede reprocharse a quien encabeza una organización que se sume a una manifestación de autotutela, inherente al derecho fundamental de libertad sindical (Artículo 19 números 16 y 19 de la Constitución Política de la República)" "47. Dicha sentencia hace referencia a su vez, al pronunciamiento de la Corte de Apelaciones de Rancagua, la cual habría indicado que "asumir como posible -sin matices- que la participación en una huelga (o 'paralización ilegal', como la designa el recurrente) pueda configurar una causal de caducidad del contrato de trabajo, merced a un ejercicio de mera subsunción, 'Significaría lisa y llanamente considerar que la ley autoriza el despido de un trabajador por ejercer ese derecho', en circunstancias que están en juego normas de principios. Lejos de ello, 'la vía del desafuero puede ser utilizada pero debe sustentarse en faltas referidas a obligaciones individuales vinculadas al escenario jurídico de la huelga, es decir, deben imputarse faltas que se han originado en un abuso del derecho fundamental, tales como las originadas en una huelga abusiva o inexistente" ${ }^{48}$. Se confunden así, el desarrollo de una huelga legal, realizada en el marco de la normativa vigente, como parte del derecho fundamental de la libertad sindical, con la huelga o paralización ilegal, la cual, contrario a como lo pretende señalar la Ilustrísima Corte de Apelaciones de Santiago, no es inherente al citado derecho fundamental.

Aun más claramente la Corte ha señalado recientemente que "ha sido superada la tesis que sustentaba que la huelga era una 'etapa indeseable' de la negociación colectiva; por lo mismo tampoco puede sostenerse que cualquier huelga que se realice fuera de la negociación colectiva sea ilícita o contraria al derecho. (...) La sola circunstancia que la ley regule la huelga para un caso, en la negociación colectiva reglada, no puede llevarnos a sostener que fuera de ella se encuentre prohibida, pues lo que es legislador ha omitido regular o definir no puede sostenerse que lo ha prohibido" 49 . Acto seguido, señala que el único límite que se contempla explícitamente es que no se trate de funcionarios del Estado, Municipalidades, o trabajadores de corporaciones o empresa de servicios de utilidad pública o cuya paralización causa grave daño al país. Se revoca así la sentencia de primera instancia, la cual es clara al establecer que éste, como todo derecho fundamental, dista de ser absoluto, y que la paralización de funciones se ampara únicamente durante un proceso de negociación colectiva, como manifestación del derecho de huelga ${ }^{50}$.

De un tenor similar es la sentencia dictada por el Juzgado del Trabajo de San Miguel, en el cual se señala que la causal de desafuero se refiere "a conductas relacionadas con la

\footnotetext{
${ }^{47}$ Redbus Urbano SA con Rojas (2013).

${ }^{48}$ Redbus Urbano $S A$ con Rojas (2013).

${ }^{49}$ Actionline Chile S.A. con Yutronicy Otro (2015).

${ }^{50}$ Actionline Chile S.A. con Yutronic y Otro (2015).
} 
prestación de servicios del trabajador dentro de la empresa, dejando afuera aquellas acciones censurables que el trabajador pudiera realizar fuera del ámbito laboral, que es lo que a juicio de esta sentenciadora ocurre en el caso particular. En efecto, este incidente ocurre mientras que los trabajadores están haciendo uso de su derecho a huelga, no durante el ejercicio de sus labores" ${ }^{51}$. Así, se analizan los efectos de la huelga en relación al contenido ético jurídico del contrato y a las obligaciones del mismo, concluyéndose que durante el periodo de huelga un trabajador no se encuentra sujeto a obligación o deber alguno propio de la relación laboral. Igual consideración se efectúa en sentencia que, indagando sobre esta materia, señala lo siguiente: "El alcance de la suspensión, entonces, dice relación con la dimensión patrimonial del contrato de trabajo. El contrato de trabajo sigue vigente, debiendo determinarse qué dimensiones obligacionales subsisten. Por cierto, subsiste aquella que dice relación con el ejercicio mismo del derecho fundamental (que en el limitadísimo espacio que la ley reserva a la huelga en el modelo normativo chileno), en la especie se desarrolla en el marco de la habilitación legal, según concuerdan las partes. La pregunta que debe plantearse entonces, es si existen obligaciones ético jurídicas en el contrato de trabajo, según postula la demandante. La respuesta es negativa; pues si bien mayoritariamente la doctrina y jurisprudencia nacional han pregonado sostenidamente su existencia, queriendo verlas indirectamente en algunas normas (causal de falta de probidad v.gr), como ha anotado acertadamente la doctrina y jurisprudencias comparadas más avanzadas, tales deberes desnaturalizados o pseudo obligaciones -a la luz de lo que aviene con una obligación contractual en forma- no son parte del contenido obligacional del contrato de trabajo, y su formulación se explica por una visión ideológica de la doctrina laboral nacionalsocialista (teorías comunitarias de la empresa) que ha postulado a la empresa como realidad socio económica al servicio de una visión negadora del conflicto" ${ }^{52}$. Pues bien, pareciera ser que, en esta materia, posee mayor relevancia para el sentenciador, la discusión relativa a los efectos de la huelga en relación a la suspensión del contrato del trabajo y sus obligaciones pertinentes, por sobre un debate en torno a la colisión de derechos fundamentales.

Interesante a este respecto resulta también el razonamiento efectuado por la Ilustrísima Corte de Apelaciones de San Miguel en torno al despido de trabajadores que, fuera de un proceso de negociación colectiva, efectuaron una paralización que implicó su despido. Así, la Corte razona que: " $1^{\circ}$ ) Que el contrato de trabajo no sólo implica un servicio a cambio de una remuneración, sino que tiene además, un contenido personal, de carácter ético- jurídico, cuya razón de ser radica en el hecho que los hombres se vinculan en una relación de carácter jurídico-personal, de manera estable y continua, en pos de un fin común, a saber, la producción de bienes y servicios para la comunidad y ello conlleva como necesaria consecuencia, que sus relaciones deben tener un contenido personal, adicional al meramente patrimonial. (...) $4^{\circ}$ ) Que así las cosas, en el caso sublite, el comportamiento desplegado por los demandantes, en cuanto a alterar la normal producción de cada turno, para obtener un beneficio en conjunto, que individualmente no habrían logrado, si bien no perjudicó los intereses económicos ni la marcha de la empresa, comprometió gravemente la confianza que el empleador había depositado en sus trabajadores e implica una trasgresión a las obligaciones ético- jurídicas del contrato de trabajo, de lealtad y fidelidad en el cumplimiento de las obligaciones que emanan de él" ${ }^{53}$. Así, estando vigente la relación laboral, cuestión que sucede en una paralización ilegal,

\footnotetext{
${ }^{51}$ Casas del Valle Barros Hermanos Limitada con Avello y Otros (2013).

52 Banco de Chile con Ortiz (2012).

${ }^{53}$ Landeros Santibañez con Coresa S.A. (2009).
} 
no puede sino concluirse que existe efectivamente una transgresión a obligaciones propias del contrato de trabajo.

Contrariando el razonamiento anterior, la Iltma. Corte de Apelaciones de Santiago concedió una solicitud de desafuero sindical fundamentado en haber concurrido la causal del $\mathrm{N}^{\circ} 5$ del artículo 160 del Código del Trabajo, esto es, actos, omisiones o imprudencias temerarias que afecten a la seguridad o al funcionamiento del establecimiento, a la seguridad o a la actividad de los trabajadores, o a la salud de éstos, por haberse presentado el dirigente sindical, junto a otros trabajadores, en las dependencias de la empresa, momento en el cual "paralizaron y entorpecieron la continuidad del servicio de transporte público que opera la actora bajo el pretexto de la realización de una fiscalización o inspección mecánica unilateral de los buses, no consentida por la empleadora, sin conocimiento de ella, sin adoptar medidas de precaución para evitar perjuicios económicos para la empresa y para evitar incomodidades a los usuarios del sector poniente que utilizan ese medio de transporte para asistir diariamente a sus trabajos" ${ }^{54}$. Se estimó que un actuar de dichas características se convertía en un acto de "sabotaje", concediéndose el desafuero. ¿Por qué se concede un desafuero sindical de este último tipo, en el cual no se incurrió en acciones de enfrentamiento o violencia alguna? Pues bien, éste último no fue un hecho desarrollado en el contexto de una negociación colectiva, contexto en el cual actualmente los Tribunales de Justicia confieren a la organización sindical un ámbito de mayor laxitud al momento de ejercer sus herramientas de presión.

Interesante resulta concluir entonces que, durante un proceso de negociación colectiva, tanto dirigente sindical como trabajador, se encontrarían autorizados para desarrollar todo tipo de conductas de fuerza, amparados bajo el derecho a huelga y la libertad sindical. Sin embargo, al dirigente sindical además se le permitiría, según la opinión mayoritaria de la jurisprudencia, participar en una paralización o huelga 'ilegal', con actos de violencia o fuerza. Esta situación sería más debatida respecto del trabajador sin cargo de representación, el cual podría ser despedido por los actos que efectúe en dicho contexto de paralización no reglada.

Una segunda opción dentro de la normativa laboral, es la solicitud de prácticas antisindicales. Sin embargo, a este respecto el enfoque sigue estando de lado de hechos que puedan ser cometidos por el empleador, siendo casi nulas las posibilidades del empleador de interponer acciones por prácticas antisindicales de los trabajadores o de las organizaciones sindicales por incurrir en actos de violencia. Profusa es por ende, la jurisprudencia que, fundadamente, sanciona al empleador por incurrir en actos de violencia o de presión que atentan contra la libertad sindical, sin que exista una gran cantidad de sentencias que busquen limitar, dentro del marco propio de la negociación colectiva, el actuar de la organización sindical, evitando y prohibiendo el uso de la fuerza por parte del otro protagonista del proceso.

Respecto al punto anterior, vale la pena citar la sentencia del Juzgado de Letras del Trabajo de Antofagasta, el cual tuvo que conocer del proceso de negociación colectiva del cual fue parte la Sociedad de Servicios Marítimos y Transportes Limitada Ultraport y su respectivo sindicato. En concreto, la Inspección Provincial del Trabajo Antofagasta dedujo denuncia por práctica antisindical contra Compañía Portuaria Mejillones, a objeto que se declarara que la

${ }^{54}$ Inversiones Alsacia con Hormazabal (2012). 
denunciada incurrió en prácticas antisindicales, en el marco de un proceso de huelga que involucró una serie de atentados en contra de la integridad física y psíquica de trabajadores de Ultraport y otras empresas del mismo puerto, y de bienes de la empresa, y donde se le prohibió el ingreso a los dirigentes sindicales que participaron de dichos hechos. Al respecto, el sentenciador indica que "para que este principio de libertad sindical pueda cumplir con su finalidad, es necesario que los trabajadores cuenten con elementos que puedan equiparar la desigualdad que subyace a las relaciones entre trabajadores y empleadores, de ahí que la huelga se transforma en un elemento esencial, que si bien no se encuentra reconocido expresamente como un derecho en nuestra Constitución Política, en nuestro país la huelga es reconocida como un derecho fundamental (...) concebida como una suspensión de faenas concertada por los trabajadores que debe de llevarse a efecto en forma voluntaria y pacífica" ${ }^{\text {" }}$. El sentenciador recoge así como parte inherente de la libertad sindical y del proceso de huelga de la negociación colectiva, el sentido pacífico de ésta. Por lo mismo, "la prohibición de ingreso a la faena de trabajadores que a juicio del mandante han vulnerado derechos fundamentales de la propia empresa, a saber, $19 \mathrm{~N}^{\circ} 24$ y de sus trabajadores como son $19 \mathrm{~N} 1$ y $19 \mathrm{~N}^{\circ} 16$, en sí misma no puede ser considerada vulneratoria de derechos, toda vez que la decisión se toma como medida de proteger sus bienes y a los trabajadores de la faena en virtud de lo dispuesto en el artículo 184, en su relación con el artículo 183 E, que obliga al dueño de la obra o faena a tomar todas las medidas necesarias y eficaces para asegurar la vida no sólo de sus trabajadores, sino además de todos aquellos que laboran en sus recintos cualquiera sea su dependencia. (...) Que, considerando entonces lo dispuesto en el párrafo cuarto del artículo 485 del Código del Trabajo que establece que se entenderán que los derechos y garantías a que se refiere el mismo artículo resultan lesionados cuando el ejercicio de las facultades que la ley reconoce al empleador limita el pleno ejercicio de aquéllas sin justificación suficiente, en forma arbitraria o desproporcionada, o sin respeto a su contenido esencial, se debe señalar que la inclusión de estos trabajadores pertenecientes al Sindicato $\mathrm{N}^{\circ} 2$ y sus adherentes, no es desproporcionada o arbitraria, puesto que se enmarca dentro de los derechos que la ley le concede al dueño de la obra o faena y tampoco se advierte que se hubiere vulnerado el derecho a la libertad sindical en su esencia, toda vez que, el impedimento de ingreso a la faena para los dirigentes sindicales no fue absoluto, ni tampoco permanente" ${ }^{, 5}$. Cabe señalar, que este fallo fue revocado en un confuso y débil pronunciamiento de la Ilustrísima Corte de Apelaciones de Antofagasta, la cual tras enumerar toda la normativa aplicable al caso, advierte que "la sentenciadora incurre en una interpretación que no ha sido acorde a la finalidad de las normas que protegen la libertad sindical" 57 .

De lo expuesto se aprecia que las medidas existentes para enfrentar situaciones de violencia en el contexto de la huelga son insatisfactorias e insuficientes. Asimismo, el procedimiento de negociación colectiva actual así como la aplicación de las diversas herramientas descritas no han evitado la violencia durante la huelga, produciéndose una sensación de impunidad e indefensión. Así, ante un eventual escenario de mayor conflicto, cabe preguntarse si no sería necesaria la incorporación de otras medidas o sanciones más acordes a la situación laboral particular en la que se producen estas situaciones de violencia en el contexto particular de naturaleza laboral, el cual podría requerir de un tratamiento especial, debiendo las partes seguir conviviendo y trabajando en conjunto.

\footnotetext{
55 Inspección Provincial del Trabajo de Antofagasta con Compañia Portuaria Mejillones S.A. (2014)

${ }^{56}$ Inspección Provincial del Trabajo de Antofagasta con Compañia Portuaria Mejillones S.A. (2014)

${ }^{57}$ Inspección Provincial del Trabajo de Antofagasta con Compañia Portuaria Mejillones S.A. (2015).
} 
En este contexto, pareciera además evidente, que la intervención policial y las órdenes restrictivas a ser impartidas no son suficientes para enfrentar posibles situaciones de violencia. Es necesario discutir y proponer medidas de carácter preventivo que busquen evitar enfrentamientos, junto a sanciones efectivas que sirvan de desincentivo para el uso de la fuerza. En este sentido, la reforma original iba en la dirección correcta buscando consagrar el carácter pacífico que debería siempre tener la huelga, explicitando de alguna forma la importancia de evitar que el derecho a huelga de los trabajadores pueda afectar otros derechos fundamentales y contemplando causales específicas de desafuero y prácticas antisindicales.

\section{CONSIDERACIONES FINALES}

En las últimas décadas, la legislación laboral chilena ha ido transformándose, buscando fortalecer los derechos tanto de los trabajadores como de las organizaciones sindicales. Sin embargo, sigue siendo necesario fortalecer aún más la acción de los sindicatos, ampliando el ámbito del proceso de negociación colectiva para poder lograr un verdadero equilibrio entre ambas partes, objetivo que la actual reforma laboral se propone. Así, se traza un horizonte destinado a promover el desarrollo de relaciones laborales modernas y equilibradas, en las cuales exista una justa retribución y un trato respetuoso entre empleadores y trabajadores.

Es en ese nuevo contexto de igualdad y comunicación, que los antiguos medios y herramientas utilizadas para relacionarse entre trabajadores, empleadores y organizaciones sindicales pierden su vigencia. Al vislumbrarse un nuevo paradigma social - laboral, en el cual ambas partes de una negociación colectiva se enfrentan ya no desde la obscuridad y el desconocimiento, sino que desde la experiencia y la comunicación, con una serie de herramientas nuevas, y en una posición de igualdad que les permite, por primera vez, conversar en un mismo plano, el uso de la fuerza deja de ser un medio que puede ser permitido. Se atenta así contra el espíritu de esta misma reforma laboral, utilizada, no para fomentar comunicación y construcción conjunta de una comunidad laboral de mejores características que genere arraigo y proyección mutua para empleador como trabajador, sino para atentar contra el mismo espacio laboral que permite al trabajador ganar su sustento, destruyendo todo espíritu de comunidad o ciudadanía que pueda existir y perjudicando espacios de trabajo y emprendimiento ciudadano en detrimento de los diversos estamentos que lo componen. Se requiere, junto a las mejoras y nuevas prerrogativas que esta reforma laboral propone e incorpora, una mirada más severa hacia el uso de la fuerza, y un énfasis más estricto en la creación de canales de comunicación y trabajo coetáneos a cualquier proceso de negociación colectiva, mirada inicialmente recogida en el proyecto de reforma laboral, y desechada erróneamente tras las indicaciones del ejecutivo.

La reforma laboral actual incorpora una serie de herramientas destinadas a fortalecer la posición de la organización sindical, haciéndose cargo de una deuda histórica legislativa en un país democrático que busca, en materia laboral, fortificar a las organizaciones sindicales como parte de la reconstrucción general del ramaje social ciudadano que existiera en nuestro país 
hasta la década del 70. Sin embargo, las modificaciones descritas deben proponerse desde el marco de una sociedad democrática que busca caminar hacia el constante diálogo y la construcción conjunta entre los diversos actores sociales de nuestro país. Siendo el objetivo final la creación de un marco normativo que asegure una negociación colectiva fluida y transparente, que permita no sólo satisfacer necesidades laborales inmediatas acordes a la actualidad económica y laboral interna de la empresa, sino que generar una serie de proyectos y objetivos comunes de larga data entre trabajadores y empleador, a través del cual ambas partes dialoguen. Esperamos que las próximas indicaciones y modificaciones al proyecto de ley en cuestión, puedan volver a poner en la mesa, estos importantes aspectos. 


\section{BIBLIOGRAFÍA}

ACNUDH (2015): “Pacto Internacional de Derechos Económicos, Sociales y Culturales.

Adoptado y abierto a la firma, ratificación y adhesión por la Asamblea General en su resolución 2200 A (XXI), de 16 de diciembre de 1966" Disponible en: $<$ http://www.ohchr.org/SP/ProfessionalInterest/Pages/CESCR.aspx>

BACHELET JERIA, Michelle (2014): “Mensaje $N^{\circ}$ 1055/362” Disponible en: <https://www.camara.cl/pley/pley_detalle.aspx?prmID=10248\&prmBoletin=9835-13>

CAAMAÑO ROJO, Eduardo (2008): "El reconocimiento de la libertad sindical y el problema de la representación de los trabajadores en la negociación colectiva", Revista de Derecho de la Pontificia Universidad Católica de Valparaíso, N³0, pp. 265-291.

CAAMAÑO ROJO, Eduardo y UGARTE CATALDO, José Luis (2008): Negociación Colectiva y Libertad Sindical. (Santiago, Chile, Editorial Legal Publishing).

COMISIÓN DE HACIENDA (2015): "Informe financiero sustitutivo del proyecto de ley" Disponible en: $<$ https://www.camara.cl/pley/pley detalle.aspx?prmID=10248\&prmBoletin=9835-13 $>$

COMISIÓN DEL TRABAJO (2015): "Informe de la comisión de trabajo y seguridad social, recaído en el proyecto de ley que moderniza el sistema de relaciones laborales, introduciendo modificaciones al Código del Trabajo" Disponible en: < https://www.camara.cl/pley/pley detalle.aspx?prmID=10248\&prmBoletin=9835-13>

DIRECCIÓN DEL TRABAJO (2008): “Orden de Servicio $\mathrm{N}^{\circ}$ 09" Disponible en: < http:/ www.google.com/url?sa $=t \& r c t=j \& q=\& e s r c=s \&$ source $=$ web\&cd $=1 \& v e d=0 C B w Q F j A$ AahUKEwix3r-

sxejIAhWBQ5AKHd5uA8o\&url=http $\% 3 \mathrm{~A} \% 2 \mathrm{~F} \% 2 \mathrm{Fwww} . d \mathrm{t} . g o b . c l \% 2 \mathrm{Ftransparencia} \% 2 \mathrm{FOrd}$ en Servicio 09 31-12-

08.doc\&usg=AFQjCNEaU2CoaHQu1z7eUJyIrf J4qdx4Q\&sig2=wbuJwEcZWYnU6u Y99T $\underline{\text { GHA\&bvm }=\text { bv.106130839,d.Y2I> }}$

Gamonal Contreras, Sergio (2002): Derecho Colectivo del Trabajo (Santiago, Editorial LexisNexis).

HUMERES MAGMAN, Héctor (2012): "La Huelga en Chile", Estudio de Derecho del Trabajo y de la Seguridad Social (Edición junio de 2012).

INTERNATIONAL FEDERATIONF MUSICIANS (2000): "Principio de la OIT sobre el Derecho de Huelga". Disponible en: <http://www.fim-musicians.org/wpcontent/uploads/right_to_strike_es.pdf> 
INTERnational LabOUR OFFICE (2015): "Promoting Collective Bargaining" Disponible en: <http://www.ilo.org/wcmsp5/groups/public/---ed_protect/---protrav/--travail/documents/publication/wcms_244335.pdf>

ORGANIZACIÓN INTERNACIONAL DEL TRABAJO (1994): Libertad sindical y negociación colectiva. Estudio general de las memorias sobre el Convenio (núm. 87) sobre la libertad sindical y la protección del derecho de sindicación, 1948, y el Convenio (núm. 98) sobre el derecho de sindicación y de negociación colectiva. (Oficina Internacional del Trabajo, Ginebra).

ORGANIZACIÓN INTERNACIONAL DEL TRABAJO (1996): La libertad sindical. Recopilación de decisiones y principios del Comité de Libertad Sindical del Consejo de Administración. (Oficina Internacional del Trabajo, Ginebra, cuarta edición).

OFICINA INTERNACIONAL DEL TRABAjO (2006): La Libertad Sindical, Recopilación de decisiones y principios del Comité de Libertad Sindical del Consejo de Administración de la OIT. (Oficina Internacional del Trabajo, Ginebra, quinta edición).

SIERRA HERRERO, Alfredo (2010): "Nueva Justicia Laboral y el Reemplazo en la Huelga", Revista de Derecho Universidad Católica del Norte, Sección: Estudios, Año 17, No 1, pp. 101-113.

VARAS CASTILLO, Mario (2003): "Libertad sindical y negociación colectiva en Chile: un diagnóstico de la Ley N $\mathrm{N}^{\circ}$ 19.759”, Boletín Oficial del Trabajo. (Gobierno de Chile, Dirección del Trabajo).

\section{NORMAS CITADAS}

D.F.L. Número 1, 31 de julio de 2002, Fija Texto Refundido y Sistematizado del Código del Trabajo.

Decreto Número 100, 17 de septiembre de 2005, Fija el Texto Refundido, Coordinado y Sistematizado de la Constitución Política de la Republica de Chile.

Convención Americana de Derechos Humanos, Costa Rica, 22 de noviembre de 1969.

\section{JURISPRUDENCIA JUDICIAL}

Landeros Santibánez. con Coresa s.a. (2009): Corte de Apelaciones de San miguel, 26 de mayo de 2009 (acción de demanda por despido injustificado).

Inversiones Alsacia Con Ormazábal (2012): Corte De Apelaciones De Santiago, 26 de septiembre de 2012 (acción de demanda de desafuero sindical).

Banco de Chile con Ortiz. (2012): Segundo Juzgado de Letras del Trabajo de Santiago, 18 de octubre de 2012 (acción de demanda de desafuero sindical). 
Redbus Urbano S.A con Rojas (2013): Corte De Apelaciones De Santiago, 4 de octubre de 2013 (acción de demanda de desafuero sindical).

Casas Del Valle Barros Hermanos Limitada con Avello y Otros (2013): Juzgado de Letras del Trabajo de San Miguel, 29 de noviembre de 2013 (acción de demanda de desafuero sindical).

Inspección Provincial del Trabajo de Antofagasta don Compañia Portuaria Mejillones S.A. (2014): Juzgado de Letras del Trabajo de Antofagasta, 17 de septiembre de 2014, (acción de denuncia de práctica antisindical).

Express de Santiago don Salinas (2014): Primer Juzgado de Letras del Trabajo de Santiago, 30 de marzo de 2015 (acción de demanda de desafuero sindical).

Comercializadora de Frutas Bagno S.A. don Esteban Segundo Villegas Méndez. (2014): Juzgado de Letras del Trabajo de San Miguel, 10 de marzo de 2015 (acción de demanda de desafuero sindical).

Sociedad Educacional San Miguel Limitada con Luis Santibañez Vargas (2014): Juzgado de Letras del Trabajo de Osorno, 17 de septiembre de 2014 (acción de demanda de desafuero sindical).

Inspección Provincial del Trabajo de Antofagasta con Compañia Portuaria Mejillones S.A. (2015): Corte de Apelaciones de Antofagasta, 10 de marzo de 2015 (acción de denuncia de práctica antisindical).

Actionline Chile S.A. con Yutronic y Otro (2015): Segundo Juzgado de Letras del Trabajo de Santiago, 7 de Julio de 2015 (acción de demanda de desafuero sindical).

Actionline Chile S.A. con Yutronic y Otro (2015): Corte de Apelaciones de Santiago, 23 de Octubre de 2015 (acción de demanda de desafuero sindical). 